\title{
Controles físico, físico-químico, químico e microbiológico dos frutos de Dimorphandra mollis Benth., Fabaceae
}

\author{
Silviane Z. Hubinger, ${ }^{1}$ Hérida R. N. Salgado, ${ }^{2}$ Raquel R. D. Moreira ${ }^{* 1}$ \\ ${ }^{1}$ Departamento de Princípios Ativos Naturais e Toxicologia, Faculdade de Ciências Farmacêuticas, \\ Universidade Estadual Paulista, 14801-902 Araraquara-SP, Brasil \\ ${ }^{2}$ Departamento de Fármacos e Medicamentos, Faculdade de Ciências Farmacêuticas, \\ Universidade Estadual Paulista, 14801-902 Araraquara-SP, Brasil
}

\begin{abstract}
RESUMO: Considerando-se a qualidade dos fitoterápicos, é importante salientar que a preocupação com esta questão inclui rigoroso acompanhamento das diferentes etapas de desenvolvimento e produção, desde a coleta do vegetal até o produto final. O controle de qualidade de drogas vegetais e seus extratos é essencial quando utilizados como matéria-prima para o desenvolvimento de fitoterápicos. Neste trabalho foram utilizadas diversas técnicas (farmacopeicas e não farmacopeicas) visando estabelecer parâmetros de qualidade dos frutos de Dimorphandra mollis Benth. (Leguminosae), popularmente conhecida como faveiro. Os resultados obtidos determinaram as características físico-químicas da droga vegetal e mostraram que o pó dos frutos e o extrato etanólico $70 \%$ de D. mollis apresentam um teor de flavonóides de 10,25\% e 17,21\%, respectivamente. A análise fitoquímica preliminar dos frutos caracterizou a presença de taninos, saponinas e flavonóides. Na análise microbiológica do extrato não houve crescimento de patógenos entre os testes realizados.
\end{abstract}

Unitermos: Dimorphandra mollis, controle de qualidade, fitoterápicos, controle físico-químico, controle microbiológico.

\begin{abstract}
Physic, physic-chemical, chemical and microbiological control of fruits of Dimorphandra mollis Benth., Fabaceae". Considering the quality of phytotherapic agents, it is important to point out that the concern with this subject includes rigorous attendance the different steps of development and production of these products, from the collection of the vegetable to the availability of the final product. The quality control for the plants and their extracts is essential when they are used in the development of phytotherapics. In this work, methodologies (pharmacopoeic and no pharmacopoeic) were employed to establish norms for the quality control of Dimorphandra mollis Benth. (Leguminosae) fruit, popularly known as faveira. Pharmacopoeic and no pharmacopoeic methodologies were employed to physic, physic-chemical, chemical and microbiological quality control. The results obtained established the physic-chemical characters of the drug and showed that the fruits and the ethanol $70 \%$ extract present a content of flavonoids of $10.25 \%$ and $17.21 \%$, respectively. The preliminary phytochemical analysis of the D. mollis fruits evidenced tannins, saponnins and flavonoids. The microbiological analysis did not present pathogenic growth among the accomplished tests.
\end{abstract}

Keywords: Dimorphandra mollis, quality control, phytotherapy, physico-chemical control, microbiologic control.

\section{INTRODUÇÃO}

As plantas representaram, durante séculos, a única fonte de agentes terapêuticos para o homem. No início do século XIX, com o desenvolvimento da química, as plantas passaram a representar a primeira fonte de substâncias para o desenvolvimento de medicamentos (Albuquerque \& Hanazaki, 2006; Zaroni et al., 2004; Hostettman et al., 2003). Atualmente, $25 \%$ dos medicamentos prescritos nos países industrializados são originários de matérias-primas vegetais (Vilegas \& Cardoso, 2007).

Muitas empresas estão conscientes das tendências de consumos e buscam novos ingredientes para incorporar aos produtos já existentes e aos que poderão ser desenvolvidos no futuro. Uma tendência que está se destacando é o aumento na procura por parte da população de produtos funcionais baseados em princípios ativos vegetais (Rocha Filho, 1995; Oliveira \& Bloise, 1995). Os consumidores vêem os fitoterápicos como uma alternativa terapêutica tão eficaz e com a mesma qualidade dos 
medicamentos sintéticos (Vilegas \& Cardoso, 2007).

Observando-se a necessidade do mercado e a falta de especificação de controle de qualidade, o presente trabalho destaca o estudo de Dimorphandra mollis Benth. (Leguminosae), conhecida popularmente como barbatimão de folha miúda, faveiro e falso-barbatimão (Cintra et al., 2002). É uma árvore muito comum encontrada nos estados do Pará, Mato Grosso, Mato Grosso do Sul, Goiás, Minas Gerais e São Paulo, sendo característica de Cerrado e de Campo Cerrado (Lorenzi, 1992, Feres et al., 2006). Não há referências sobre a ocorrência desta espécie em outras partes do mundo (Lorenzi, 1992). O pericarpo do fruto é utilizado popularmente para o tratamento de úlceras, pela sua propriedade antiinflamatória e cicatrizante (Lorenzi, 1992, Cintra et al., 2002). Estas propriedades se devem principalmente a composição química das cascas e do pericarpo dos frutos de $D$. mollis, que é representada basicamente por flavonóides, principalmente, rutina e quercetina (Sousa et al., 1991, Ferreira et al., 2001; Feres et al., 2006). O presente trabalho teve por objetivo o desenvolvimento de parâmetros de controle de qualidade dos frutos de D. mollis.

\section{MATERIAL E MÉTODOS}

\section{Coleta e preparo do material vegetal}

O estudo foi realizado com os frutos de Dimorphandra mollis coletados no campus da Faculdade de Ciências Farmacêuticas da UNESP-Araraquara, localizado a S21\%48'51,4"; W48 $12^{\circ} 05,1^{\prime \prime}$ e $661 \mathrm{~m}$ de altitude. A exsicata está depositada no Herbário do Instituto de Biociências da UNESP, Rio Claro-SP, sob o número HRCB 47735. Os frutos frescos maduros colhidos foram submetidos à secagem em estufa com ar circulante à temperatura de $40^{\circ} \mathrm{C}$, até a estabilização do peso.

\section{Perda por secagem do fruto fresco em estufa com ar circulante}

Cerca de $100 \mathrm{~g}$, exatamente pesados, da droga vegetal fresca foram colocados para secagem em estufa de ar circulante à temperatura de $40{ }^{\circ} \mathrm{C}$. Foram pesados diariamente até peso constante. Os resultados foram expressos em perda de substâncias voláteis e/ou água percentual, pela media de três determinações (Mello \& Petrovick, 2000).

\section{Moagem do material vegetal}

Após a secagem dos frutos, executou-se a moagem em moinho de facas. Este processo objetivou reduzir os tamanhos das partículas de modo a aumentar, posteriormente, seu contato com o líquido extrator.

\section{Análise granulométrica}

Baseado na Farmacopéia Brasileira (1988) e com o objetivo de padronizar a granulometria do pó obtido dos frutos secos de D. mollis, $25 \mathrm{~g}$ do pó dos frutos moídos foram submetidos à passagem forçada por vibração, através de tamises com abertura de malhas correspondentes a 0,$125 ; 0,177 ; 0,420 ; 0,840 ; 2,00 \mathrm{~mm}$, utilizando-se tamisador vibratório, na escala dez do aparelho, durante trinta minutos. Após este processo, as frações foram retiradas dos tamises e do coletor e quantificadas quanto às suas proporções. Este procedimento foi realizado em triplicata. Para os estudos de passagem e retenção a partir da quantidade de pó dos frutos recolhida de cada tamis, foram elaboradas planilhas no software $\operatorname{Exel}^{\circledR}$, onde foram calculadas as freqüências percentuais e também as freqüências percentuais cumulativas.

\section{Determinação da densidade aparente não compactada do pó dos frutos}

Para este teste, utilizou-se uma proveta de $250 \mathrm{~mL}$, que foi previamente pesada. Preencheu-se a proveta com o pó dos frutos até a marca de $250 \mathrm{~mL}$. Em seguida, a proveta cheia foi novamente pesada. Do peso final, foi subtraído o peso da proveta vazia e calculou-se a densidade aparente não compactada do pó por meio da relação massa/volume do pó (Farmacopéia Brasileira, 1988). Este procedimento foi repetido três vezes com três amostras distintas.

\section{Determinação da perda por dessecação do pó dos frutos em balança com infravermelho (INFRATEST)}

Amostras de $4 \mathrm{~g}$ do pó dos frutos, exatamente pesadas, foram submetidas ao aquecimento $\left(110^{\circ} \mathrm{C}\right)$ por raios infravermelhos pelo período de aproximadamente uma hora. Após este período foi feita a determinação do peso. Esse procedimento foi realizado de hora em hora até que o peso não variasse mais do que $0,25 \%$. Os valores foram expressos em porcentagem $(\mathrm{p} / \mathrm{p})$, pela média de três determinações (Mello \& Petrovick, 2000).

\section{Determinação do pH}

De acordo com a Farmacopéia Brasileira (2000), uma solução a $1 \%(\mathrm{p} / \mathrm{v})$ do pó dos frutos em água foi aquecida até ebulição em chapa-elétrica por $5 \mathrm{~min}$. Após este tempo foi realizada uma filtração em funil contendo algodão como elemento filtrante. Após o resfriamento mediu-se o pH do filtrado e da água utilizando-se potenciômetro previamente calibrado. Os resultados foram expressos pela média de três determinações.

\section{Determinação do teor de cinzas totais}

Foi calcinado previamente o cadinho de porcelana 
em mufla a $450{ }^{\circ} \mathrm{C}$ por 30 min. $\mathrm{O}$ mesmo foi resfriado em dessecador (15 min) e seu peso foi determinado em balança analítica. Foram pesados exatamente $3 \mathrm{~g}$ do pó dos frutos, os quais foram distribuídos de maneira uniforme e submetidos à calcinação em mufla à temperatura de 450 $0 \mathrm{C}$ por duas horas. A amostra foi deixada em dessecador para arrefecimento durante $30 \mathrm{~min}$ e pesagem posterior. Os resultados forma expressos em porcentagem em peso de cinzas na droga seca $(\%, \mathrm{p} / \mathrm{p})$ e representando a média de três determinações (Farmacopéia Brasileira, 2000).

\section{Determinação de cinzas insolúveis em ácido}

As cinzas obtidas na determinação de cinzas totais foram fervidas por $5 \mathrm{~min}$ com $25 \mathrm{~mL}$ de ácido clorídrico SR (10\%) e filtrada em papel de papel de filtro isento de cinzas Filtrac ${ }^{\circledR} d=90 \mathrm{~mm}$. O papel contendo as cinzas foi lavado com água quente e as cinzas foram incineradas a uma temperatura em torno de $800{ }^{\circ} \mathrm{C}$ até peso constante. A porcentagem de cinza insolúvel em ácido foi calculada com referência ao material vegetal utilizado no início do ensaio de teor de cinzas totais (Farmacopéia Brasileira, 2000).

\section{Determinação do teor de extrativos}

Segundo Mello \& Petrovick (2000), cerca de 1 $\mathrm{g}$ do pó dos frutos, exatamente pesado, foi submetido à decocção com $100 \mathrm{~mL}$ de água, durante $10 \mathrm{~min}$. Após o resfriamento, o volume foi completado a $100 \mathrm{~mL}$. A solução obtida foi filtrada em papel de filtro e os primeiros $20 \mathrm{~mL}$ foram desprezados. Do restante do filtrado, pesou-se uma alíquota equivalente a $20 \mathrm{~g}$, em pesa-filtro previamente tarado e evaporou-se até secura em banho de água, sob agitação constante. $\mathrm{O}$ resíduo foi colocado em estufa, à temperatura de $105^{\circ} \mathrm{C}$ por $3 \mathrm{~h}$. Em seguida, resfriado em dessecador e pesado. $\mathrm{O}$ teor de extrativos foi calculado em massa percentual, pela média de três determinações segundo a equação:

$$
T E=\frac{G^{*} F D^{*} 100}{M}
$$

Onde:

$\mathrm{TE}=$ teor de extrativos $(\% ; \mathrm{m} / \mathrm{m}), \mathrm{G}=$ massa de resíduo seco $(\mathrm{g}), \mathrm{M}=$ massa da amostra $(\mathrm{g}), \mathrm{FD}=$ fator de diluição (5).

\section{Análise fitoquímica premilinar}

Essas análises objetivaram estabelecer a caracterização de diferentes classes de princípios ativos através de reações químicas segundo Costa (1994): 1) saponinas (teste de formação de espuma); 2) flavonóides (reações de Taubock, Pew, Shinoda, cloreto férrico e cloreto de alumínio); 3) taninos (reações de gelatina, cloreto férrico e acetato de chumbo); 4) alcalóides (reações de Dragendorff, Bertrand, Bouchardat, Mayer); 5) glicosídeos cardiotônicos (reações de Legal, Kedde, Pesez, Keller-Killiani e Liebremann Burchard); 6) antraquinonas (reação de Borntrager).

\section{Preparo do extrato}

A preparação do extrato hidro-alcoólico foi realizada através do método de turboextração com etanol $70 \%$ (v/v), utilizando-se a proporção de $100 \mathrm{~g} / 1000 \mathrm{~mL}$ entre soluto/solvente. Logo após, foi realizada a filtração em papel de filtro qualitativo. O solvente orgânico foi evaporado através da utilização de evaporador rotatório a $40{ }^{\circ} \mathrm{C}$. Após completa evaporação do etanol, o extrato foi liofilizado e armazenado em frasco âmbar fechado hermeticamente e sob refrigeração.

\section{Determinação do teor de flavonóides totais no pó dos frutos e no extrato etanólico $70 \%$}

Inicialmente, uma curva padrão com quercetina dihidratada, tomada como substância de referência, foi construída. Alíquotas de 2 a $6 \mathrm{~mL}$ de solução etanólica de quercetina, a $50 \mu \mathrm{g} / \mathrm{mL}$, foram transferidas para balões volumétricos de $25 \mathrm{~mL}$, contendo $1 \mathrm{~mL}$ de solução de cloreto de alumínio a $2,5 \%$. O volume final de cada balão foi ajustado com etanol. Como branco do sistema, $1 \mathrm{~mL}$ da solução aquosa de cloreto de alumínio diluído em balão de $25 \mathrm{~mL}$ foi utilizada. Decorridos $30 \mathrm{~min}$, foi tomada a leitura de cada solução a $425 \mathrm{~nm}$, em espectrofotômetro. Para quantificação de flavonóides na amostra de pó dos frutos, $200 \mathrm{mg}$ do pó foram extraídos por maceração em $10 \mathrm{~mL}$ de metanol $80 \%$ por $2 \mathrm{~h}$, obtendo-se a solução A (Funari \& Ferro, 2006).

Para quantificação de flavonóides na amostra do extrato etanólico $70 \%$, foi preparada a solução A com 0,2 $\mathrm{mg}$ do extrato dissolvidos em $10 \mathrm{~mL}$ de etanol. Utilizouse $2 \mathrm{~mL}$ da solução A para o mesmo procedimento da solução de quercetina e posterior leitura a $425 \mathrm{~nm}$, em espectrofotômetro (Funari \& Ferro, 2006).

\section{Contagem total de microrganismos no extrato etanólico $70 \%$}

Foram transferidos, assepticamente, $10 \mathrm{~g}$ do extrato etanólico $70 \%$ para $90 \mathrm{~mL}$ de solução tampão fosfato $\mathrm{pH} 7,2$, para a contagem dos microorganismos totais. A amostra 1:10 foi submetida à agitação durante $10 \mathrm{~min}$. Após a homogeneização, foi pipetado $1 \mathrm{~mL}$ da amostra 1:10 e adicionados $20 \mathrm{~mL}$ de ágar tioglicolato para bactérias e Sabouraud para leveduras, a $47{ }^{\circ} \mathrm{C}$ em placa de Petri, que foram colocadas em estufa a $35^{\circ} \mathrm{C}$ por $24 \mathrm{~h}$ e $25^{\circ} \mathrm{C}$ por sete dias, para a pesquisa de bactérias e fungos, respectivamente. Após este período, foi realizada a 
contagem do número de colônias com o auxílio de contador de colônias, calculando o número de unidades formadoras de colônia (UFC/g) (USP, 2003; Pinto et al., 2003).

\section{Pesquisa de Salmonella sp e Escherichia coli}

Foram transferidos, assepticamente, $10 \mathrm{~g}$ do extrato etanólico $70 \%$ para $90 \mathrm{~mL}$ de caldo lactosado, para a pesquisa de Salmonella sp e E. coli, incubados a $35^{\circ} \mathrm{C}$ durante 24 a $48 \mathrm{~h}$. Após este período, $1 \mathrm{~mL}$ do caldo lactosado foi transferido para dois tubos contendo caldo tetrationato e caldo selenito cistina, que forma incubados a $35^{\circ} \mathrm{C}$ por $24 \mathrm{~h}$. Após este período, a amostra foi semeada do caldo tetrationato para um tubo contendo ágar verde brilhante e duas placas de Petri contendo ágar xiloselisina-desoxicolato (XLD) e ágar bismuto sulfito. Foi realizado da mesma forma com a amostra inoculada no caldo selenito cistina, transferindo para os três meio, os quais foram incubados a $35{ }^{\circ} \mathrm{C}$ por $24 \mathrm{~h}$. O crescimento e as características das colônias foram observados. As colônias suspeitas foram semeadas com alça reta em tubo contendo ágar tríplice açúcar ferro (TSI) e incubado a 35 ${ }^{\circ} \mathrm{C}$ por 24 h. A confirmação da Salmonella foi feita pelo método de Gram (USP, 2003; Pinto et al., 2003).

Na pesquisa de E. coli, $1 \mathrm{~mL}$ do caldo lactosado foi transferido para placa contendo ágar Mac Conkey e incubados a $35^{\circ} \mathrm{C}$ por $24 \mathrm{~h}$. As colônias suspeitas forma semeadas em ágar eosina-azul de metileno (EMB) e incubadas a $35^{\circ} \mathrm{C}$ por $24 \mathrm{~h}$. A confirmação de E. coli foi realizada através do método de Gram (USP, 2003; Pinto et. al., 2003).

\section{Pesquisa de Staphylococcus aureus e Pseudomonas aeruginosa}

Foram transferidos, assepticamente, $10 \mathrm{~g}$ do extrato etanólico $70 \%$ para $90 \mathrm{~mL}$ de caldo peptonado, para a pesquisa de $S$. aureus e $P$. aeruginosa e incubados a $35^{\circ} \mathrm{C}$ por 24 a $48 \mathrm{~h}$. Após este período, uma alçada foi semeada em placas de ágar Vogel Johnson e ágar cetrimida, para a pesquisa de $S$. aureus e $P$. aeruginosa, respectivamente. As placas foram incubadas a $35{ }^{\circ} \mathrm{C}$ por 24 h. As características das colônias forma observadas e a confirmação foi realizada pelo método de Gram (USP, 2003; Pinto et. al., 2003).

\section{RESULTADOS E DISCUSSÃO}

Seguindo as exigências da resolução RDC $n^{\circ}$ 48/2004 da Agência Nacional de Vigilância Sanitária e a ausência de estudos de controle da qualidade, foi traçado o perfil farmacognóstico da droga vegetal $D$. mollis, em consonância com as exigências legislativas e, de tal forma, que pudesse colaborar com preceitos da qualidade para a droga vegetal proposta (Anvisa, 2004).

Os frutos foram mantidos em estufa de ar circulante à temperatura de $40{ }^{\circ} \mathrm{C}$ por sete dias, quando atingiram peso constante. $\mathrm{O}$ resultado da perda por secagem do fruto foi de $30,58 \%$ (Tabela 1 ). A determinação da perda por secagem de materiais vegetais se mostra importante, pois impede que o material permaneça úmido devido a uma secagem ineficiente ou que haja degradação de compostos por secagem excessiva.

Após a secagem e a moagem do material vegetal, é importante determinar o tamanho das partículas do pó que se está trabalhando, portanto realizou-se a análise granulométrica do pó. A aplicação da análise estatística dos resultados obtidos demonstrados na Figura 1 e na Tabela 1 permitiu detectar um diâmetro médio de partículas de $0,633 \mathrm{~mm}$, caracterizando um pó moderadamente grosso (WHO, 1998). Segundo a literatura (List \& Schmidt, 2000), a o tamanho das partículas da droga pulverizada representa uma influência direta sobre a eficiência no processo extrativo pois, para aqueles que envolvem filtração, o pó muito fino (abaixo de $0,125 \mathrm{~mm}$ ) pode favorecer o entupimento do filtro.

As análises físico-químicas envolveram a determinação da perda por dessecação em balança com infravermelho, determinação da densidade aparente nãocompactada, determinação do $\mathrm{pH}$, determinação do teor de cinzas totais e insolúveis em ácido e determinação do teor de extrativos. Realizou-se também as análises fitoquímica preliminar qualitativa e química quantitativa para determinação do teor de flavonóides totais nos frutos de D. mollis (Tabela 1).

A determinação da perda por dessecação do pó dos frutos de $D$. molis foi realizada em balança de infravermelho à temperatura de $110^{\circ} \mathrm{C}$, apresentando uma perda de 7,37\% (Tabela 1), quando ocorreu estabilização do processo. Este tipo de análise é importante uma vez que pode fornecer informações importantes com referência ao armazenamento da droga vegetal. A água residual encontrada na droga vegetal seca está diretamente relacionada com o seu correto armazenamento, que pode acarretar na perda do material por contaminação microbiana ou degradação por ação enzimática dos constituintes químicos. Pode-se afirmar que os valores característicos da perda por dessecação, além de informação importante do ponto de vista tecnológico, servem também como parâmetro de controle de qualidade do pó dos frutos de D. mollis. O limite máximo recomendado de umidade para drogas vegetais é de 14\% (Simões et al., 2004) e por isso constatou-se que o pó dos frutos analisado apresentou resultado satisfatório.

O valor de $\mathrm{pH}$ de $D$. mollis foi de 4,54, utilizandose água com $\mathrm{pH}$ de 5,77, o que sugere a presença de substâncias ácidas no farmacógeno estudado.

Quanto à determinação do teor de cinzas totais e cinzas insolúveis em ácido, os teores encontrados foram de $7,03 \%$ e de $2,22 \%$ respectivamente para o pó dos frutos de faveiro. Em se tratando de drogas vegetais, o principal objetivo deste tipo de ensaio é a verificação de impurezas 
inorgânicas não-voláteis que podem estar presentes como contaminantes (Farmacopéia Brasileira, 2000).

Com o objetivo de avaliar-se a quantidade de substâncias extraíveis, denominado teor de extrativos, e de acordo com a Organização Mundial da Saúde (WHO, 1998), empregou-se a decocção em etanol $70 \%$. O rendimento encontrado foi de $27,52 \%$. No entanto, é importante levar em consideração a substância que se deseja extrair. Por exemplo, para flavonóides foi demonstrado que a mistura etanol/água é eficiente para a extração desses compostos de alta polaridade.

Plantas medicinais produzem diferentes substâncias químicas (alcalóides, taninos, flavonóides, saponinas entre outros) (Barbosa-Filho et al., 2007, 2008; Saúde-Guimarães et al., 2007; Corrêa et al., 2008) e o fazem em diferentes proporções, dependendo do habitat, do regime de chuvas, da insolação, do solo, enfim, das características climáticas-edáficas (Santos et al., 2006; Andrade et al., 2007; Blank et al., 2007). Entretanto, algumas substâncias químicas são bastantes características para um determinado vegetal, e desta forma podem servir como parâmetro para sua caracterização e identificação (César et al., 2007; Migliato et al., 2007; Nascimento et al., 2008). Os dados da análise fitoquímica preliminar, realizados com frutos de D. mollis mostraram a presença de taninos condensados: reação de gelatina positiva (precipitação), reação do cloreto férrico positiva (coloração verde) e reação de acetato de chumbo negativa; saponinas: formação de espuma e flavonóides: reação de Taubock positiva (fluorescência amarelo-esverdeada), reação de Pew positiva (coloração vermelha), reação de Shinoda positiva (coloração vermelha), reação de cloreto férrico positiva (coloração verde) e reação cloreto de alumínio positiva (fluorescência amarelo-esverdeada), caracterizando a classe a flavonol.

De acordo com a literatura, os frutos de D. mollis são caracterizados pela presença de flavonóides (Sousa et al., 1991, Ferreira et al., 2001; Feres et al., 2006). Esta informação justifica a realização do doseamento deste grupo de substâncias (Tabela 1). O doseamento de flavonóides realizado do pó dos frutos e do extrato etanólico $70 \%$ de D. mollis detectou a presença de $10,25 \%$ e $17,21 \%$ de flavonóides respectivamente. Tais valores estão de acordo com a literatura, que afirma que o teor de flavonóides do fruto de D. mollis varia entre 10 e $15 \%$ (Sousa et al., 1991).

Além dos aspectos físico-químicos, o controle microbiológico é indispensável para garantir a qualidade do material botânico. Em geral, os materiais vegetais contêm um grande número de fungos e bactérias pertencentes a sua microbiota natural ou que são introduzidos durante a sua manipulação, e esta contaminação pode ser intensificada com o tempo e não comprometer somente o material em si, mas também o usuário (Migliato et al., 2007). Portanto, procurou-se realizar um controle microbiológico do extrato etanólico $70 \%$ obtido a partir dos frutos de $D$. mollis.

Os resultados obtidos do controle microbiológico do extrato de D. mollis (Tabela 2) permitiram observar que não houve crescimento microbiano de Salmonella sp, Escherichia coli, Satphylococcus aureus e Pseudomonas aeruginosa, considerados microorganismos patogênicos. $\mathrm{O}$ crescimento de fungos e bactérias esteve dentro dos limites permitidos $\left(10^{3} \mathrm{UFC} / \mathrm{g}\right.$ e $10^{5} \mathrm{UFC} / \mathrm{g}$, respectivamente) para extratos vegetais (WHO, 1998). Na contagem do número total de fungos, houve crescimento inferior a $10 \mathrm{UFC} / \mathrm{g}$ e para bactérias ocorreu o crescimento de $300 \mathrm{UFC} / \mathrm{g}$.

Tabela 1. Análises física, físico-química e química do pó dos frutos de Dimorphandra mollis.

\begin{tabular}{ll}
\hline Parâmetros & Resultados obtidos \\
\hline Diâmetro médio das partículas & $0,633 \mathrm{~mm}$ \\
Densidade aparente não compactada & $0,56 \mathrm{~g} / \mathrm{cm}^{3}$ \\
Perda por secagem & $30,58 \%$ \\
Perda por dessecação & $7,37 \%$ \\
pH & 4,54 \\
Teor de cinzas totais & $7,03 \%$ \\
Teor de cinzas insolúveis em ácido & $2,22 \%$ \\
Teor de extrativos & $31,8 \%$ \\
Triagem fitoquímica preliminar & Taninos condensados, saponinas e flavonóides (classe flavonol) \\
Teor de flavonóides totais (pó dos frutos) & $10,25 \%$ \\
Teor de flavonóides totais (extrato etanólico $70 \%$ ) & $17,21 \%$ \\
\hline
\end{tabular}


Tabela 2. Análise microbiológica do extrato etanólico 70\% obtido a partir dos frutos de Dimorphandra mollis.

\begin{tabular}{lll}
\hline Microrganismos & Recomendação* & Resultados obtidos \\
\hline Bactérias aeróbias & $\leq 10^{5} \mathrm{UFC} / \mathrm{g}$ & $300 \mathrm{UFC} / \mathrm{g}$ \\
Fungos e leveduras & $\leq 10^{3} \mathrm{UFC} / \mathrm{g}$ & Inferior a $10 \mathrm{UFC} / \mathrm{g}$ \\
Enterobactérias & $\leq 10^{3} \mathrm{UFC} / \mathrm{g}$ & Ausente \\
Escherichia coli & Ausência & Ausente \\
Salmonella sp & Ausência & Ausente \\
Staphylococcus aureus & Ausência & Ausente \\
Pseudomonas aeruginosa & Ausência & Ausente \\
\hline
\end{tabular}

*Fonte: WHO 1998; Pinto et al., 2003; USP 2003.

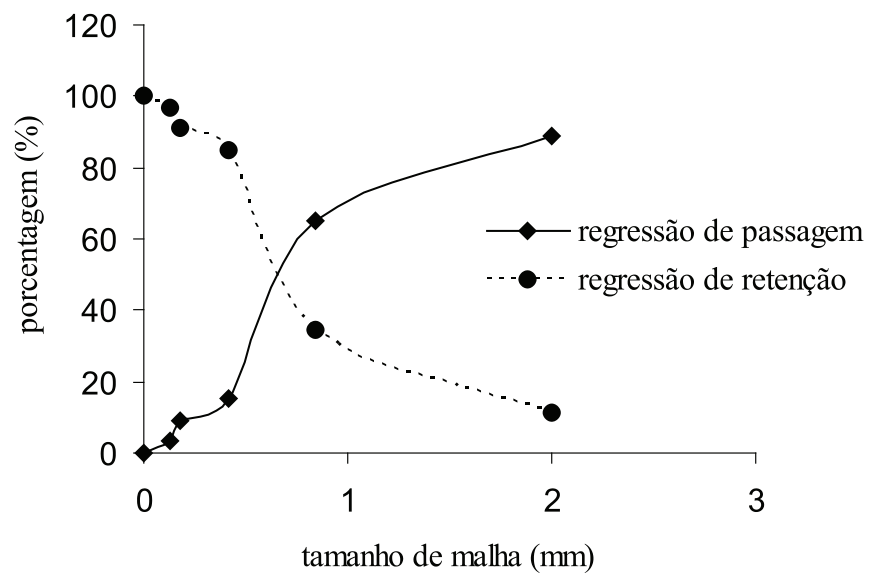

Figura 1. Tamanho médio das partículas do pó dos frutos de Dimorphandra mollis. Media de três determinações.

\section{CONCLUSÃO}

As metodologias empregadas foram adequadas para avaliar a qualidade da droga vegetal em estudo. Todas as etapas realizadas no presente trabalho são importantes e devem ser recomendadas como parâmetros seguros para o controle de qualidade do pó dos frutos de Dimorphandra mollis. Muitos dos resultados obtidos se encontram dentro de parâmetros pré-estabelecidos na literatura para drogas e extratos vegetais.

\section{AGRADECIMENTOS}

Ao Luís Eduardo dos Santos, técnico do Laboratório de Farmacognosia da Faculdade de Ciências Farmacêuticas, Unesp, Araraquara, e a Maria de Fátima Rodrigues, técnica do laboratório de Controle de Qualidade da Faculdade de Ciências Farmacêuticas, Unesp, Araraquara, pelo apoio técnico.

\section{REFERÊNCIAS}

Albuquerque UP, Hanazaki N 2006. As pesquisas etnodirigidas na descoberta de novos fármacos de interesse médico e farmacêutico: fragilidades e perspectivas. Rev Bras Farmacogn 16 (Supl.): 678-689.

Andrade CA, Costa CK, Bora K, Miguel MD, Miguel OG, Kerber VA 2007. Determinação do conteúdo fenólico e avaliação da atividade antioxidante de Acacia podalyriifolia A. Cunn. ex G. Don, Leguminosae-mimosoideae. Rev Bras Farmacogn 17: 231-235.

Anvisa 2004. Agência Nacional de Vigilância Sanitária, Brasil, Leis, decretos, etc. Resolução no 48, de 16 de março de 2004. Dispõe sobre o registro de medicamentos fitoterápicos. Diário Oficial da República Federativa do Brasil, Brasília.

Barbosa-Filho JM, Nascimento-Júnior FA, Tomaz ACA, Athayde-Filho PF, Silva MS, Cunha EVL, Souza MFV, Batista LM, Diniz MFFM 2007. Natural products with antileprotic activity. Rev Bras Farmacogn 17: 141-148.

Barbosa-Filho JM, Alencar AA, Nunes XP, Tomaz ACA, SenaFilho JG, Athayde-Filho PF, Silva MS, Souza MFV, da-Cunha EVL 2008. Sources of alpha-, beta-, gamma-, 
delta- and epsilon-carotenes: A twentieth century review. Rev Bras Farmacogn 18: 135-154.

Blank AF, Costa AG, Arrigoni-Blank MF, Cavalcanti SCH, Alves PB, Innecco R, Ehlert PAD, Sousa IF 2007. Influence of season, harvest time and drying on Java citronella (Cymbopogon winterianus Jowitt) volatile oil. Rev Bras Farmacogn 17: 557-564.

César IC, Braga FC, Vianna-Soares CD, Nunan EA, Barbosa TAF, Moreira-Campos LM 2007. Determinação de daidzeína, genisteína e gliciteína em cápsulas de isoflavonas por cromatografia em camada delgada (CCD) e cromatografia líquida de alta eficiência (CLAE). Rev Bras Farmacogn 17: 616-625.

Cintra P, Malaspina O, Petacci F, Fernandes JB, Bueno OC, Vieira PC, Silva FGF 2002. Toxicity of Dimorphandra mollis to Workers of Apis mellifera. J Braz Chem Soc 13: 115-118.

Corrêa MFP, Melo GO, Costa SS 2008. Substâncias de origem vegetal potencialmente úteis na terapia da Asma. Rev Bras Farmacogn 18 (Supl.): 785-797.

Costa AF 1994. Farmacognosia. III vol. 5 ed. Lisboa/ Portugal: Fundação Calouste Gulbenkian/Oficina A. Coelho Dias S.A.

Farmacopéia Brasileira 1988. 4 ed. São Paulo: Atheneu.

Farmacopéia Brasileira 2000. 4 ed. São Paulo: Atheneu.

Feres CAO, Madalosso RC, Rocha OA, Leite JPV, Guimarães TMDP, Toledo VPP, Tagliati CA 2006. Acute and chronic toxicological studies of Dimorphandra mollis in experimental animals. J Ethnopharmacol 108: 450-456.

Ferreira RA, Botelho AS, Davide AC, Malavasi MM 2001. Morfologia de frutos, sementes, plântulas e plantas jovens de Dimorphandra mollis Benth. - faveira (LeguminoseaeCaesalpinioideae). Rev Bras Bot 24: 303-309.

Funari CS, Ferro VO 2006. Análise de própolis. Cienc Tecnol Aliment 26: 171-178.

Hostettmann K, Queiroz EF, Vieira PC 2003. Princípios ativos de plantas superiores. São Carlos: EdUFSCar, p. 09, 6061.

List PH, Schmidt PC 2000. Phytopharmaceutical Technology. Florida, CRS Press.

Lorenzi H 1992. Árvores Brasileiras: manual de identificação e cultivo de plantas arbóreas nativas do Brasil. Nova Odessa: Editora Plantarum.

Mello JCP, Petrovick PR 2000. Quality control of Baccharis trimera (Less) DC (Asteraceae) hydroalcoholic extracts Acta Farm Bonaerense 19: 211-215.

Migliato KF, Moreira RRD, Mello JCP, Sacramento, LVS, Correa MA, Salgado HRN 2007. Controle de qualidade do fruto de Syzygium cumini (L.) Skells. Rev Bras Farmacogn 17 : 94-101.

Nascimento EA, Chang R, Morais SAL, Piló-Veloso D, Reis DC 2008. Um marcador químico de fácil detecção para a própolis de Alecrim-do-Campo (Baccharis dracunculifolia). Rev Bras Farmacogn 18: 379-386.

Oliveira LC, Bloise MI 1995. Extratos e óleos naturais vegetais funcionais. Cosmet Toiletries 7: 30-37.

Pinto TJA, Kaneko TM, Ohara MT 2003. Controle biológico de qualidade de produtos farmacêuticos, correlatos e cosméticos. 2. ed. São Paulo: Atheneu, p. 81-98, 261280.

Rocha Filho PA 1995. Fitocosméticos. Cosmet Toiletries 7: 1820.

Santos SC, Costa WF, Batista F, Santos LR, Ferri PH, Ferreira
HD, Seraphin JC 2006. Seasonal variation in the content of tannins in barks of barbatimão species. Rev Bras Farmacogn 16: 552-556.

Saúde-Guimarães DA, Faria AR 2007. Substâncias da natureza com atividade anti-Trypanosoma cruzi. Rev Bras Farmacogn 17: 455-465.

Sousa MP, Matos MEO, Matos FJA, Machado MIL, Cravetro AA 1991. Constituintes químicos ativos de plantas medicinais brasileiras. Fortaleza: Universidade Federal do Ceará

United States Pharmacopeia 2003. Ed. Rockville: United States Pharmacopeial Convection, 26, p. 1877-1879, 2380.

Vilegas W, Cardoso CAL 2007. Controle químico de qualidade de fitoterápicos e plantas medicinais. In: Yunes RA, Cechinel Filho V. Química de produtos naturais, novos fármacos e a moderna farmacognosia. 1 ed. Itajaí: Univali.

WHO - World Health Organization 1998. Quality control methods for medicinal plant materials. Geneva.

Zaroni M, Pontarolo R, Abrahão WSM, Fávero MLD, Correa Junior C, Stremel DP 2004. Qualidade microbiológica das plantas medicinais produzidas no Estado do Paraná. Rev Bras Farmacogn 14: 29-39. 